\title{
A Critical Reflection on Transformative Learning as Experienced by Student-Teachers during School-Based Learning
}

\author{
K. E. Khabanyane \\ School of Education Studies, University of the Free State \\ mokhethi6@gmail.com \\ J.R. Maimane \\ School of Education Studies, Central University of Technology \\ maimanejr@cut.ac.za

\section{J. Ramabenyane} \\ School of Social Sciences and Languages, University of the Free State \\ ramabenyanemj@ufs.ac.za
}

Doi:10.5901/mjss.2014.v5n27p452

\section{Abstract}

Transformative learning is defined as the process of effective change in a frame of reference. It is based on the Transformative Theory developed by Jack Mezirow. . He advocates critical reflection on experiences, so as to experience a perspective transformation. Mezirow argues that "reflection involves a critique of assumptions to determine whether the belief acquired through cultural assimilation in childhood, remains functional for us as adults". This study finds transformative learning relevant to South African school contexts, since the definition of 'school' in this country is heavily loaded with different meanings denoting various attributes. The communities are also varied in their cultures, languages, socio-economic standards, and residential areas previously determined by race. Some perspectives of transformative learning are discussed. They are consciousness-raising, critical reflection, development, individuation and the existential process. The school-based university students engaged in transformative pedagogy at the different schools. The application of learning through the existential process caused change in perspectives of various people at school. The study, consequently, recommends existential process for the transformative pedagogy.

Keywords: Transformative learning, frame of reference, perspectives, transformation as consciousness-raising, critical reflection, development, Individuation, existential process, transformative pedagogy, school-based university students.

\section{Introduction}

Transformative learning is defined simply by some literature as the process of effective change in a frame of reference (Mezirow, 1991, 1997). It is also defined by others as learning that induces more far-reaching change in the learner than other kinds of learning, especially learning experiences which shape the learner and produce a significant impact, or paradigm shift, which affects the learner's subsequent experiences (Cranton, 1994, 1996)

The study of transformational learning emerged with the work of Jack Mezirow $(1981,1994,1997)$. Three common themes characterized Mezirow's theory of the mechanism of transformational learning in the classroom. These were experience, critical reflection, and rational discourse. Through this combination of reflection and discourse, the student was able to make shifts in his/her world view which produced a more inclusive world-view. Mezirow identified rational discourse as a catalyst for transformation, as it induced the various participants to explore the depth and meaning of their various world-views. He emphasizes that transformative learning is rooted in the way human beings communicate. For Mezirow, one of the benefits of transformational learning was the development of greater autonomy as a person (Mezirow (1997).

The process of transformative learning is based on the Transformative Theory which was originally developed by Jack Mezirow in 1981. The theory is described as being "constructivist, as an orientation which holds that the way learners interpret and reinterpret their sense experience is central to making meaning; and hence learning" (Mezirow, 
1991). The theory's major components are the meaning structures (perspectives and schemes). Meaning perspectives are defined as "broad sets of predispositions resulting from psycho-cultural assumptions which determine the horizons of our expectations" (Mezirow, 1991). They are divided into 3 sets of codes: sociolinguistic codes, psychological codes, and epistemic codes. A meaning scheme is "the constellation of concept, belief, judgment, and feelings which shapes a particular interpretation" (Mezirow, 1994, 223). The earliest writer on transformational learning (Mezirow, 1981) developed the concept of "meaning perspectives" as one's overall world-view, and that of "meaning schemes" as the smaller components which contain specific knowledge, values, and beliefs about one's experiences. An explanation given is that a number of meaning schemes work together to generate one's meaning perspective; and that the meaning perspectives are acquired passively during childhood and youth. The point further made is that these acquired meaning perspectives are the target of the transformation that occurs through experience during adulthood; and that they operate as perceptual filters that determine how an individual will organize and interpret the meaning of his/her life's experiences. Transformative learning' theory says that the process of "perspective transformation" has three dimensions: psychological (changes in understanding of the self), convictional (revision of belief systems), and behavioural (changes in lifestyle).

Mezirow asserts that meaning structures are understood and developed through reflection; and that "reflection involves a critique of assumptions to determine whether the belief, often acquired through cultural assimilation in childhood, remains functional for us as adults" (Mezirow, 1991). He urges people to engage in critical reflection on their experiences, so as to experience a perspective transformation. He, however, points out that for some people any explanation of an idea suffices to them, especially if given by a teacher, an authority, people who are highly respected because of power or of the dominant culture from where they come. For those it does not matter even if the explanation is clearly uncritically assimilated. This also applies to the giver of the explanation; he/she expects the listener to believe fully what he/she is being told without reflecting on it (Mezirow, 1997).

One of the main points in his work with transformative learning is the division of knowledge into three distinct types: the instrumental, communicative and emancipatory. The two former types are, on one hand, considered the most common types of technical and practical knowledge, in which the instrumental learning focuses on learning through taskoriented problem solving and determination of cause and effect relationships, while the communicative learning involves how individuals communicate their feelings, needs and desires. The emancipatory dimension beholds, on the other hand, the notion that everyone possesses the potential to break free from their own situation to transform their own life. This requires an awareness of one's current life conditions.

He also proposes four ways of learning, which are refining or elaborating our meaning schemes, learning new meaning schemes, transforming meaning schemes, and transforming meaning perspectives" (Mezirow, 1991).

This study will address the concept of transformative learning as embedded in these ways of learning. Although the Transformational Learning Theory originated as a theory referring to adult learning, this study finds it to also be relevant to the school contexts as experienced in South Africa.

Referring to a school in the South African context is to refer to a rather complicated concept. The definition of a school in this country is not a straight forward one since this concept is, in this context, heavily loaded with different meanings denoting various attributes. The various communities in this country are so varied in culture, languages, beliefs, socio-economic standards, types of upbringing, behaviour, sections of residents previously determined by race, and many other ways, that it is not impossible for them to have skewed frames of references. The schools are designated by their areas of location (Ruperti, 1976; and Giliomee \& Schlemmer, 1989). As a result, the behaviour of learners varies in accordance with the context in which their schools are situated (Fleisch, 2008). While they may be classified as those of the either rural or urban areas they are also classified according to race. Although this race idea may now be retracted as a historical fact, on the claim that schools are open to learners of all races during the current democratic government, the bulk of learners of a particular race is still found in the school of their historic race. To some extent people from the adjacent communities have started joining those on the neighbouring communities; who are in most cases different in culture and values. Mezirow alludes that the type of the frame of reference that is created from outside, through associations, values, and beliefs, i.e. the structures of assumptions we have made for ourselves in order to understand our experiences, delimit our perceptions and activities.

In order to have a clearer focus our study the following section will highlight the different perspectives in which transformative learning is defined. From them the study will choose the one that is suitable for the transformational pedagogy in the classrooms at schools.

\section{Transformative Learning Defined}

There are various perspectives of transformative learning that are highlighted by literature. Dirk argues that what 
transformative learning means and how it is best fostered within formal learning settings vary considerably, and that it depends on one's theoretical perspective. He gives a lengthy explanation of each of the views that the transformative educators have assumed about transformative learning. By borrowing a term 'strand' from Clark (1993) he suggests that there are four different 'strands' of thought within the research and theory on transformative learning (Dirkx, 1998). In this section we will, firstly, go through these four strands of thought and try to understand what transformative learning means and involves as articulated by the pioneers in those four perspectives, Paulo Freire, Jack Mezirow, Larry Daloz, and Robert Boyd. We shall also refer to an existential approach to transformative learning as the fifth perspective. Lastly, we shall look at how these first four cognitive approaches, as well as the fifth experiential approach contribute to a pedagogical framework.

\subsection{Transformation as Consciousness-raising}

For Paulo Freire (1970) transformative learning is emancipatory and liberating, because education aims at fostering critical consciousness among individuals. Critical consciousness refers to a process in which learners develop the ability to analyse, pose questions and take action on the social, political, cultural, and economic contexts that influence and shape their lives (Dirkx 1998:3). Freire argues that education fosters freedom among learners because it enables them to reflect on their world and, thereby, change it. According to Freire transformative learning is consciousness-raising; and he refers to it as conscientization. His contention is that learning helps adults develop a deeper understanding of the ways in which the social structures shape and influence the way they think about themselves and the world. He maintains that it provides people with a voice, with the ability to name the world, and that in so doing, they can construct for themselves the meaning of the world (Dirkx 1998:3).

This means that in a South African classroom the teacher must take a stand and make learners aware of the influence of the social structures around them that have bound them in and dictate to them how they should define themselves. The learners must be conscientised about the way the world has shaped their frames of reference, and that they have the power to change those frames of reference by constructing their own meaning of the world. In other words the teacher can use Freire's ideas within the transformative pedagogy. This the teacher can do by fostering critical consciousness among the learners, by making them to develop the ability to analyse contexts that influence and shape their lives. They must learn to pose questions and to take action on the contexts, such as the social, political, cultural, economic, contexts and many others.

\subsection{Transformation as Critical Reflection}

Mezirow maintains that it is important that adult learning emphasise contextual understanding, critical reflection on assumptions, and validation of meaning by assessing reasons (Mezirow, 2009; Taylor, 2000; Taylor \& Cranton, 2012; and Henderson, 2012). This argument he bases on the observation that we tend to have an urgent need to understand and order the meaning of our experience. This, he explains, we do by integrating the new meaning with what we know because we want to avoid the threat of chaos. He points out, furthermore, that for now the justification of what we know depends on the context in which our knowledge is embedded. This goes well for our beliefs, values and feelings. Because of this state of affairs learning is understood as the process of using a prior interpretation to construe a new or revised interpretation of the meaning of one's experience as a guide to future action (Kitchener 1983 in Taylor and Cranton, 2012). Mezirow refers to Langer (1977:4) explaining the concepts 'mindlessness' and 'mindful' learning as the former involving relying on past forms of action and previously established distinctions and categories, while the latter is defined as the continuous creation of new categories, openness to new information, and an implicit awareness of more than one perspective (Taylor \& Cranton, 2012). Mindfulness and comprehension, he argues, have different degrees with regard to becoming aware of one's thought. For instance, knowing how we know, our values and feelings involve awareness of the contexts of our interpretations and beliefs and those of others, like sources, nature and consequences in the adulthood level. At this level the informed decisions require also critical reflection on the validity of our assumptions or premises (Taylor \& Cranton, 2012:76). During the process of transformative learning we transform our taken-forgranted frames of reference to make them more inclusive, discriminating, open, emotionally capable of change and reflection. This way our frames of reference may generate beliefs that will prove more justified to guide action. Transformation theory focuses on how we learn to negotiate and act on our own purposes, values, feelings and meanings to gain greater control over our lives as socially responsible, clear-thinking decision makers; rather than the purposes, values, feelings and meanings we have assimilated from others uncritically (Taylor \& Cranton, 2012). 
In the South African schools described above the teacher can also use this critical reflection in the transformative pedagogy. It will be important for the teacher to advise the learners to be aware of the contexts that have formed their frames of references, such as their learned cultural beliefs, values, feelings and meanings, and to, therefore, strive for contextual understanding, critical reflection on assumptions, and validation of meaning by assessing reasons. It must be explained to them that learning occurs either by elaborating existing frames of references, by learning new frames of reference, by transforming points of view, or by transforming habits of mind (Taylor \& Cranton, 2012).

\subsection{Transformation as Development}

Dirkx expounds that according to Daloz something that motivates adults to participate in formal learning experiences is the need to find and construct meaning within their lives. This ability to make sense of our experiences Daloz sees as related to the developmental movement of our lives. The 'movement into new developmental phases requires the adult learner to construct new meaning structures that help them perceive and make sense of their changing world' (DirkX, 1998). This means that during adulthood the development tasks require the replacement of the old ways of making meaning with the more appropriate ones for the current demands. As a result adults learn to shift from their old ways of making sense of their lives, as well as their sense of self, and to move towards a new construction of self. The Transformative learning for Daloz is more oriented to personal change than to social change. It deals more with the psychosocial and developmental context in which much of adult learning seems to take place. He demonstrates in narratives that 'the content and the processes of these learning experiences can serve to disrupt old patterns of meaning and encourage the construction and formation of new ways of seeing the self and the world' (Dirkx, 1998).

In this case learners in the South African context can be encouraged to learn and understand the content well so as to increase their knowledge about the world and the self. This development in thinking may change their frames of reference and make them think like adults, and no more like young learners whose minds are not well developed yet (Cranton, 1996, 2006).

\subsection{Transformation as Individuation}

Boyd (as cited in Imel, 1998) differed from Mezirow's views in two major ways. First, he believed the emotional/kinesthetic component, rather than the rational component of the transformational experience was the major catalyst for change. Second, he believed the desired outcome of transformation was not autonomy, but a greater interdependent and compassionate relationship with other people

Dirkx refers to Boyd and Myers (as cited in Imel, 1998) considering grieving to be a critical phase in transformational learning, as the student realizes that old patterns of thinking, perceiving, beliefs and values are giving way to new patterns. He explains that Boyd wrote that transformative education draws on the realm of interior experience, one constituent being the rational expressed through insights, judgements, and decision; the other being the extrarational expressed through symbols, images, and feelings (Dirkx, 1998).

Dirkx highlights the fact that Boyd is working from the perspective of depth psychology, from particularly the work of Carl Jung. According to Boyd knowledge of ourselves and the world is mediated largely through symbols. He describes the symbols as images that are powerful or some motifs that hold considerable significance for us since they represent deep-seated issues and concerns, at an unconscious level, that may be evoked through the study of content or subject matter. Meaning-making involves processes of recognising, naming and elaborating these images within conscious awareness. Through these processes learners gain insight into those aspects of themselves that remain hidden from conscious awareness, yet serve to influence and shape their sense of self, their interpretations of their external world. In this perspective the goal of transformative learning is to identify these images that arise within the learning process and to establish an intrapersonal dialogue with them, which is a representation of a constructive relationship between the conscious and ego and the less conscious aspects of the psyche or Self. The ego is, however, not recognised as a powerful player in the larger arena of the psyche or Self. What is found to be more significant are the unconscious structures that populate the psyche. Boyd suggests that the process of transformative learning involves establishing a relationship and on-going dialogue with these structures. According to Boyd this dialogue is part of a broader process that is naturally on-going within us all, which Jung refers to as individuation (Dirkx, 1998). Boyd is more concerned with the expressive or emotional-spiritual dimensions of learning, and with integrating these dimensions holistically and consciously within our daily experience of life. He maintains that adult learners do this by making the unconscious conscious; that is, becoming aware of aspects of themselves of which they are not conscious. Dirk argues that although scholars have explored education from the perspective of depth psychology for a long time, from as far back as Anna 
Freud's (1947) advice to school teachers and parents, Boyd's work lacks a distinct and clearly articulated pedagogical framework (DirkX, 1998)

\subsection{Transformative learning as Existential Process}

Willis gives an explanation of the existential approach to learning as an approach that points out that learning, particularly transformative learning, is a personal dynamic process. He states that it is made up of a series of chosen acts of selforientation in response to some life challenges. He refers to this approach as the one with a perspective that looks to the actual processes of human existence, to the processes of human being and becoming. His approach differs from others as categorised by Cranton (2006) as those that came up as an outcome of critical thinking (Freire and Merirow) and of non-rational thinking (Boyd \& Myers, Dirkx, Cranton), which he believes are the essentialist structural approaches that look at changes to the cognitive structures.

Transformative learning, Wills elucidates, can be understood as an existential act which engages the whole person of the learner. From this perspective such learning involves significant personal change and is identified by learners themselves as transformative. In order to describe the existential quality of such a transformative learning event we turn to a suggestion by Heron (1992) that the experience of human knowing and learning involves four interconnected modalities. The first modality refers to the form of embodied sensation and feeling, which is generated in the initial awareness of new sensation and feeling. The learner feels physical resonance, that is, he or she has bodily responses that are involved in some transformative narratives. Stories can have the ability to represent the existential dimensions of transformative learning. This does happen within what the historian of ideas Jack Cross (2005) refers to as the three recurring dialectic tensions that require on-going resolution characterising the existential outlook, which are 'existence and transcendence', 'choice and boundary situations', and 'self and other'. He explains that from the existential perspective transformative learning refers to radical learning choices by which a person orients her- or himself wisely and authentically within the forces of these dialectics (Wills in Taylor \& Cranton 2012). The second modality refers to how the sensation and feeling are experienced. They are experienced as metaphoric, intuitive and heartfelt image creation. In this mode of knowing, the imaginal according to Heron, the learner sees and dwells on the sensations or feelings of the first mode in a metaphoric and narrative way. This mode is linked to the significant personal change that the learner may identify as transformative; he or she produces a metaphoric or imaginal presentation of the power and reach of the learning experience (Wills in Taylor \& Cranton 2012). Hillman (1981) and Corbin (1969) clarify that imaginal knowing is not the same as the workings of the imagination, which are broader and full of real and unreal possibilities. They emphasise that imaginal processes are no concerned with fantasy; but that they are linked to images through which people consciously or unconsciously represent and value things and experiences, seemingly instinctively and often without full awareness. These images, according to Hillman (1981), are supported by 'generative' images that hold the imagination and move the heart, the influence of which is somehow present deep in the person's psyche. He explains, furthermore, that this imaginal approach suggests that these personal generative images and ideals are influenced by powerful, more or less hidden images, which Jung calls archetypes, which are located in the unconscious mind. According to Macdonald (1981); Holland \& Garman (2008) this imaginal representation of an experience of transformative knowing and learning is linked to human mythopoesis which is the creation of significant life-interpreting and life-guiding stories.

The third modality involves conceptual analysis and critique. It is the foundation of logical rational approaches to transformative knowing and learning. Wills maintains that this is the radical moment of intellectual insight when chaotic and disturbing questions are in some way brought to resolution. This leads to a reflective action, also called praxis, as a fourth modality. During these experiential dimensions of analytical and critical elements, the question posed by Wills is 'What does this transformative process feel like for the learner?' (Taylor \& Cranton, 2012). This is the existential inquiry into self-defined transformative learning that explores the lived experience of the fourth mode of knowing and learning. This final mode refers to the feedback from chosen action. This suggests that the transformative thinking, feeling, and imagining lead to new knowledge and ways of being in the world. It then takes another dimension when put into action in the context of embodied life with others. When Kasl and Yorks (2002) explored Heron's approach in relation to transformative learning they summarised the four modalities of Heron as being a cycle in which the learner starts by experiencing a felt encounter, which is grasped and presented intuitively, and then expressed propositionally, and then extended into practical action. The last phase which completes the cycle, which is the action creates a new experience of 'felt encounter'. The existential dimensions can be represented naturally in stories as well, whereas the cognitive forms of transformative knowing and leaning can be presented in logical reports written logically and carefully (Taylor \& Cranton, 2012). 
The teacher who prefers an existential approach can encourage the learners to follow Heron's cycle of modalities in order to change their perspectives. As existentialists it is through praxis, a reflective action, based on the analysis and the critique of concepts that a new experience of 'felt encounter' can be created.

The following section will demonstrate how the frames of reference of learners in schools and those of their teachers were changed through a transformative pedagogy by one of the school-based university students. It will also explain how this university student's involvement in transformative learning managed to transform her negative perspective about her class in the school she was allocated to during a teaching practice session.

\section{Transformative Pedagogy for the School-Based University Students}

The objective of the Central University of Technology (CUT) students to transform the school-going learners' frames of reference was achieved by most of them. These were the students who were registered for a Post Graduate Certificate in Education (PGCE), who went to schools in the nearby community for their annual teaching practice session, in 2014, as a requirement for their Professional Teaching module. In their endeavour towards promoting transformation in schools they engaged in transformative pedagogy as directed by the Transformational Learning Theory. This they approached from various perspectives of transformative learning.

Some reported back, after the practical teaching session, to have engaged in the Ferarian perspective of transformation as consciousness-raising while in schools. Since some of them had never before been in the community set-ups such as those whose schools they visited for teaching practice, which are characterised by poverty, badly damaged roads, heavily overcrowded classrooms, schools with inferior-looking buildings in many different ways and schools with highly lacking teaching and learning modern resources, and mostly ignorant-of-current-affairs learners, even those in higher levels of learning, they were highly amazed by the new learning context they were experiencing there. This raised their consciousness regarding the South African politics and history. They started analysing their own social, political, cultural and economic contexts. They became conscious of the fact that the past South African system of 'apartheid' created communities of highly varying characters. They noticed the 'rift' between the communities, demarcating one community as having been advantaged while the others as having been disadvantaged by the past system regarding everything good for life. They understood the psychological effect the 'apartheid' system had on the life of those in disadvantaged communities. This led to their engagement in a critical reflection of their assumptions and stereotypes about people of other cultures who come from communities other than their own. They then decided to do things differently to the learners. They handled them with respect and encouraged them to learn through positive reinforcements. This motivating action transformed the learners' assumptions about themselves. The learners realised that they could make it if they worked harder.

Others told interesting stories about their engagement in transformative pedagogy with learners in schools. These stories revealed the student teachers' engagement in transformative learning as existential process, that is, as personal dynamic processes. One student in this category related a complete story about her experiences and involvement with her class. As an outsider to the community of her learners she was experiencing their culture, languages and their lifestyle for the first time in her lifetime. She already had some assumptions about the type of learners she was going to teach during the practice teaching session. These assumptions included some negative stereotypes that she had learned from her own social context. Initially she was always irritated by the learners' behaviour both in class and outside. She noticed that in class they were too shy to answer questions and to speak to her. They seemed not to have interest in what she was saying, because they always bowed their heads instead of looking straight in her eye in saying whatever needed to be said. She found them to be rather too noisy outside and appeared to be rowdy when approaching each other. This experience made her to have negative feeling about this class. She even requested her university lecturer to remove her from that 'estranged' school and to rather place her in a 'better' one. By that she was referring to those in her own community. The refusal to her proposal forced her to think otherwise. She realised that she could change the situation in that context and turn it to the one she could experience with pleasure. She decided to act otherwise, in order to realise her new vision.

Fitting her story to Heron's suggestion about the experience of human knowing and learning, which involves four modalities that are interconnected, we can see that her story has gone through all these four modalities of knowing and learning. The first modality is represented by the student teacher's unbearable feeling about the new unfamiliar context in which the learning process takes place. This modality is generated in the initial awareness of such sensations and feelings. She started by experiencing a 'felt encounter'. She then grasped and experienced it intuitively. That means she dwelled on those sensations in a metaphoric way. This represents the second modality in which her second mode of knowing was that of being involved in an imaginal process, which is linked to the images through which she consciously 
represented that experience. When she started analysing and critiquing what she had experienced it became the moment of her intellectual insight which she expressed propositionally to demonstrate the logical rational approach to transformative knowing and learning. This signified the third modality. This led to her reflective action, the praxis, which was the actual practical action, as a fourth modality. This action created for her a new experience of 'felt encounter'.

The action she took was to start a new project with the same learners whose behaviour she had found disturbing.. In her first step she made use of a 'Eureka tool', as put well by Wegerif that it is a way of 're-representing things to see them from different perspectives or points of view.' (Wegerif, 2011). Taking it from Archimedes' 'Eureka' insight Wegerif alerts that the 'Eureka' experience is never a cultural tool which always embodies previous solutions; but that it is always new and unique. This means that it is not the case that all our thinking is mediated by our cultural tools. He illuminates that Archimedes' source of his 'Eureka' insight was to focus not on the object, which was the target for his solution, but on the background to the object.

While teaching the formal curriculum in class this student teacher changed the focus of her teaching a bit. She focussed more effectively on their project she started for afterschool. The project itself was not based on the curriculum for this class or level. It was not even related to the subject matter they were busy with. She requested her learners to remain after school in order to learn a few things from the computer. When they enjoyed the first exercise she added some more exercises bit by bit. These included a lesson on how to create a website. Her persuasion that the sharpening of their skills on their own would enable them to be in contact with her at the university gave them more enthusiasm. They enjoyed the computer lessons so much that they became open to her and enjoyed learning even the content from their prescribed curriculum. Their grades improved and they showed a great deal of appreciation to their teacher, the same student teacher. During the lesson evaluation session by the university lecturer the learners cooperated very well with the student teacher and wished her well in her evaluation. They also expressed their love to her as their teacher. They pleaded with her to come back to their school to be with them every time after school even after the teaching practice session.

The student teacher reported that the learners' frames of reference were transformed towards university students who regularly come to their school to practice teaching, as well as towards the learning content they had always thought was too difficult to grasp. She also admitted that the whole existential process transformed her perspective and her frame of reference about the learners and the school. The teachers also realized only then that their learners were actually quite intelligent.

\section{Conclusion}

Now that we have gone through all the five perspectives of transformative learning, with the first four as the cognitive approaches and the fifth one as the experiential approach we have noticed how easier it was for the transformational pedagogy in the classrooms at schools to go along with the experiential approach, the existential approach. Although the teacher can use the discussed cognitive approaches to encourage learners to change their perspectives on some believes it seems the practical action to change the behaviour is more appropriate for transformational pedagogy. The study, therefore, recommends the use of the existential approach for the transformational pedagogy. In other words while the teacher can always foster critical consciousness among the learners, by making them to develop the ability to analyse contexts that influence and shape their lives, or can advise them to strive for contextual understanding, critical reflection on assumptions, and validation of meaning by assessing reasons, the learners' perspectives and behaviour may not necessarily be changed by the knowledge acquired to analyse and to reflect. This also goes for learners' encouragement to construct new meaning structures that help them perceive and make sense of their changing world, or to identify the images at an unconscious level, elaborating them within conscious awareness and establish an intrapersonal dialogue with them to establish a relationship and on-going dialogue with them, the learners' perspectives and behaviour may also not necessarily be changed by the knowledge acquired to construct new meaning structures and to establish a relationship and dialogue with the images at an unconscious level.

The study recommends the use of the existential approach for the transformational pedagogy, because this approach is referred to as the one with a perspective that looks to the actual processes of human existence, to the processes of human being and becoming. It is viewed as an existential act which engages the whole person of the learner. From this perspective such learning involves significant personal change and is identified by learners themselves as transformative. 


\section{References}

Boyd, R., 1991. Personal transformation in small groups: a Jungian perspective. London: Routledge.

Cranton, P., 1994. Understanding and promoting transformative learning: A guide for educators of adults. San Francisco: Jossey-Bass.

Cranton, P., 1996. Professional Development as Transformative Learning: New Perspectives for Teachers of Adults. San Francisco, CA: Jossey-Bass Inc.

Cranton, P., 2006. Understanding and Promoting Transformative Learning: A Guide for Educators of Adults (2nd ed.). San Francisco, CA: John Wiley \& Sons, Inc.

Dirkx, J. M., 1998. Transformative Learning Theory in the Practice of Adult Education: An Overview. PAACE Journal of Lifelong Learning, Volume 7, pp. 1-14.

Fleisch, B., 2008. Primary Education in Crisis. Why South African schoolchildren underachieve in reading and mathematics. Cape Town, South Africa: Juta \& Co, Ltd.

Giliomee, H. \& Schlemmer, L., 1989. From Apartheid to nation-building. Contemporary South African debates. Cape Town, South Africa: Oxford University Press.

Henderson, J., 2012. Transformative learning: Four activities that setthe stage. Fostering a climate conducive to transformative learning| Faculty Focus, 17(January), pp. 1-5.

Mezirow, J., 1990. Fostering Critical Reflection in Adulthood. San Francisco: Jossey-Bass.

Boyd, R., 1991. Personal transformation in small groups: a Jungian perspective. London: Routledge.

Cranton, P., 1994. Understanding and promoting transformative learning: A guide for educators of adults. San Francisco: Jossey-Bass.

Cranton, P., 1996. Professional Development as Transformative Learning: New Perspectives for Teachers of Adults. San Francisco, CA: Jossey-Bass Inc.

Cranton, P., 2006. Understanding and Promoting Transformative Learning: A Guide for Educators of Adults (2nd ed.). San Francisco, CA: John Wiley \& Sons, Inc.

Dirkx, J. M., 1998. Transformative Learning Theory in the Practice of Adult Education: An Overview. PAACE Journal of Lifelong Learning, Volume 7, pp. 1-14.

Fleisch, B., 2008. Primary Education in Crisis. Why South African schoolchildren underachieve in reading and mathematics. Cape Town, South Africa: Juta \& Co, Ltd.

Giliomee, H. \& Schlemmer, L., 1989. From Apartheid to nation-building. Contemporary South African debates. Cape Town, South Africa: Oxford University Press.

Henderson, J., 2012. Transformative learning: Four activities that setthe stage. Fostering a climate conducive to transformative learning| Faculty Focus, 17(January), pp. 1-5.

Mezirow, J., 1990. Fostering Critical Reflection in Adulthood. San Francisco: Jossey-Bass.

Mezirow, J., 1991. Transformative Dimensions of Adult Learning.. San Francisco, CA: Jossey-Bass..

Mezirow, J., 1997. Transformative Learning: Theory to Practice. New Directions for adult and Continuing Education, 74(Summer), pp. 511.

Mezirow, J., 1997. Transformative Learning: Theory to Practice. New Directions for Adult and Continuing Education, 74(Summer), p. 512.

Mezirow, J., 2000. Learning as Transformation: Critical Perspectives on a Theory in Progress. San Francisco: Jossey Bass.

Mezirow, J., 2009. Transformative Learning in Practice: Insights from Community, Workplace and Education. s.l.:Jossey-Bass Inc.

Muller, C., 1969. Five hundred years; A history of South Afrioca. Pretoria and Cape Town: Academica.

Ruperti, R., 1976. The education system in Southern Africa. Pretoria: J. L. van Schaik.

Taylor, E. W., 2000. Fostering Mezirow's transformative learning theory in the adult education classroom: A critical review. CJSAE, 14,2(November), pp. 1-28.

Taylor, E. W. \& Cranton, P. a. A., 2012. The handbook of transformative learning. Theory, Research, and Practice. San Francisco, CA: Jossey-Bass.

Wegerif, R., 2011. Mind Expanding. Teaching for thinking and creativity in primary education. Berkshire, England: Open Unuiversity Press. 